\title{
THE DAVIDS AND THE GOLIATHS: INVESTMENT DYNAMICS AND PERFORMANCE DIFFERENTIALS OF SMALL FIRMS AND FAMILY- CONTROLLED LARGE FIRMS IN FOUR SECTORS OF THE INDIAN MARKET
}

\section{Jaideep Ghosh'}

1. School of Management and Entrepreneurship, Shiv Nadar University, India

* Corresponding Author: Jaideep Ghosh, Shiv Nadar University, India, $\triangle$ Email: jghosh20770@gmail.com

\begin{abstract}
This study explores investment dynamics based on interlocking directorates and performance differentials of two kinds of publically traded firms operating in the Indian market: Non-affiliated, small firms and family-controlled, large firms. Considering four important sectors (fashion; manufacturing; transport; food) of the Indian market, this study finds that a significant fraction of the small firms are able to maintain stable performance over time by forging strategic ties with similar other firms in transactional supply-chain modes, although many large, family-controlled firms dominate sections of the market. Firm board interlocks play a crucial role in strategizing investment decisions and tie-forging processes for the small firms. This study contributes to a deeper understanding of the question concerning how investments of small firms might be governed through interfirm ties of coordinated and cooperative activities. The results have important implications for small firms operating in the markets of a number of emerging economies of the world.
\end{abstract}

Keywords: Firm investment structures; Non-affiliated, small firms; Family-controlled, large firms; Firm performance; Firm board interlocks

\section{Introduction}

A question of major theoretical and empirical interest concerns how capital investment structures of small-sized $^{1}$, non-affiliated ${ }^{2}$ (SNA) firms enable them to compete in a market, significant sections of which are dominated by large, family-controlled (LFC) firms ${ }^{3}$. Earlier scholars have investigated various aspects of this question (Carney, 2005; Claessens \& Fan, 2002; Daily \& Dollinger, 1992; Klapper \& Love, 2004; La Porta et al., 1999; Miller et al., 2008; Randolph et al., 2021), which have important implications for many emerging economies. In this paper, we examine this question by closely looking at the dynamics of investments and performances of these firms over time. We test our model using empirical data from four important sections of the Indian industry: fashion; manufacturing; transport; and food.

\footnotetext{
' We only investigate stock-listed companies. Firms are considered "small" if they are much smaller than "large" firms in terms of their total asset holdings, total sales, market values of equity, and the number of employees.

2 In this paper, "non-affiliated" refers to firms that are not controlled by any business families.

${ }^{3} \mathrm{~A}$ few of these firms are even multinationals, which are commonly called emerging economy multinational enterprises (EEMNES)
} 
With large concentrations of a family's wealth in a group of LFCs, the family promoters, by dint of their substantial ownership stakes and influential positions on the firm boards, dictate major governance policies for the firms under their direct leadership, which are motivated primarily by their personal attitudes, ideas, objectives, policies, and politics. Over the years, this phenomenon has come to govern the dynamics of the Indian market in multiple sectors of the industry (Chakrabarti et al., 2008; Gollakota \& Gupta, 2006; Khanna \& Rivkin, 2001; Ray et al., 2018; Selarka, 2005). Importantly, LFCs are not always single-family concerns where ownership and control are limited to single-family units (Litz, 1995). These Goliaths of the industry could even be controlled by the immediate and extended members of influential business families, with first cousins, second cousins, in-laws, parents, grandparents, uncles, aunts, and possibly many other relations of blood or marriage serving as promoters or outside directors on the firm boards (Jackling \& Johl, 2009; Khanna \& Palepu, 2000; Westhead et al., 2001).

Since colonial times and even after India's independence in 1947, these LFCs, with their select and influential (and sometimes politically powerful!) coterie of family members, community stalwarts, and political advisors have controlled large sections of the Indian market (Bajpai, 2016; Gollakota \& Gupta, 2006; Kumar \& Singh, 2013). These firms - the Goliaths of the industry - vary in size and age, as well as in their degree of diversification, but in time, their influence spreads across sectors to dominate the market that includes other players, such as the Davids of the industry - the SNAs (Manos et al., 2007; Zahra \& Pearce, 1989).

Some recent work notwithstanding, this critical issue has remained somewhat underrepresented in the extant literature on many emerging economies. The present study does not claim to present a theoretical model to explain the issue in all facets of it. Rather, the study is exploratory in nature. In particular, it makes evaluative analyses of the investment and performance differentials of SNAs in comparison with those of LFCs operating in the Indian market. Specifically, it contributes to this literature in two ways. First, it finds that, although SNAs continuously contend with the powerful spatiotemporal advantage enjoyed by influential LFCs, many SNAs do perform consistently well. These firms are empowered by large-scale, open-market conditions in the Indian market today, along with opportunities for global business transactions, internationalization, and improved corporate governance policies instituted by market regulators in recent years. Second, the study explores conditions under which SNAs are able to withstand the dominant competitive pressure of LFCs by strategically leveraging board-interlocked resources in proliferating transactional relationships with allied firms not only in the same industry sector but also across different ones. To be effective, the firms make carefully chosen, judiciously planned, and purposeful investments in capital expenditures to enhance their internal efficiency as well as to make their interfirm business operations more productive, smooth, and profitable. They develop, in this way, a select coterie of firms in order to be able to compete in the market, which critically determines their future survival and growth 4 . This strategy constitutes the bedrock of their competitive advantage and business support.

\footnotetext{
${ }_{4}$ Indian LFCs also participate in supply-chain networks (Bajpai, 2016). However, because they are strongly family-controlled, a large number of family members or extended relations of promoters sit on their boards as outside directors, simply supporting all decisions taken by the promoters. The non-functional, decorative role of these directors does not help in making networking connections for strategic investments for the company (Gollakota \& Gupta, 2006). Therefore, although LFCs engage in interlocking directorates and collaborative activities, the large family dominance of their boards makes them much less efficient than SNAs in terms of reducing risks and increasing chances of success by making strategic decisions for networked investments (Kumar \& Singh, 2013).
} 


\section{Capital Investments}

\subsection{Theoretical considerations}

Primarily, firms engage in two modes of investments. First, for running core operations utilizing labor, infrastructure, technology, plants, machinery, other equipment, and so on, essential investments vary from one firm to another and depend on the internal requirements of a firm in diverse channels of its business operations (Almeida \& Campello, 2007; Booth et al., 2001; Short, 1994). Second, the investment structures for interfirm supply-chain networked transactions transcend the specifics of any particular firm (Baiman \& Rajan, 2002; Paulraj et al., 2008; Rungtusanatham et al., 2003). These latter types of investments are coordinated with allied investments of firms' supply-chain partners and are needed to reduce interfirm transactional non-uniformities. The capital investment objective is to not only enhance the firm's internal performance but also to ensure transactional smoothness across the chain of firms brought together through their focused, interlinked operations (Bidault \& Salgado, 2001; Huggins, 2010; Kapoor, 2014; Parmigiani \& Mitchell, 2009). A principal mechanism by which the supply-chain partnering process is facilitated lies in board interlocks of firms, in which independent directors are selected on the firm board from its partner firms and in the degree to which resources brought into the firm by these directors can be effectively leveraged (Ingley et al., 2017).

For firms to effectively perform their business operations in supply-chain modes, investments in asset procurement and utilization are necessary to meet the demands of their supported operations (Cousins \& Menguc, 2006; Thomas \& Griffin, 1996). Enhanced investment coordination with partners serves to maximize future cash flows as well as to reduce short-term oscillations and volatilities in production and support functions (Baiman \& Rajan, 2002; Craighead et al., 2007). In a growth-driven mode, a firm's supplier-base expands over time, in response to which well-directed investments are made by firms to cope with rising demands for increasing inventory turnover, stocking facilities, trade receivables, and other asset forms (Bidault \& Salgado, 2001; Lee et al., 1997). Further investments must also be made to enlarge relevant distribution channels of the consumer-base to meet specific requirements for cash flows and material resources. These investments must be directed to ensure that transactions down the supply chain are largely free from undesirable oscillations (Thomas \& Griffin, 1996).

In order to establish a balance, interfirm operations must be reconciled with those that are needed for internal production effectiveness and efficiency. The investments depend on a number of factors, including, for instance, firm age, size, and industry; equity and debt positions; number and skill-levels of employees; current capacity utilization; and so on (Almeida \& Campello, 2007). Whereas interlinked investments benefit from interfirm knowledge and resources, firm-specific investments depend on a firm's internal capacities and requirements for knowledge and resources and do not require external input in order to be functional (Nise, 2015). However, in making strategic investment decisions, there frequently arises a tension between these investment modes. Nevertheless, a balance may eventually emerge. If it does, then levels of internal investments can be reconciled with degrees of interfirm investments under prevailing market conditions. The balance ensures a uniformity between the investment modes and enhance financial performance over time.

\subsection{Firm Connectivity Structure}

A large fraction of SNAs in India capitalizes on strategic investments by means of transaction-linked relationships with similar other firms in order to find expanding opportunities (Gollakota \& Gupta, 2006; Goswami, 2002; Sankar et al., 2015). Prior research has also shown that small firms benefit from strategic investments in order contend with market dominance exercised by large firms by virtue of their size, financial strength, and marketing power (Young et al., 2014). In this regard, resource dependence theory underscores the critical resource provision role played by the firm board (Hillman \& Dalziel, 2003). Board directors facilitate the creation of relationships with an organization's external environment (Pfeffer \& Salancik, 1978), serve as channels between the organization and its investors 
(McDonald et al., 2008), and help company executives identify potential growth linkages through financial ties that include infrastructure setup, internal loans, and debt opportunities (Bandyopadhyay \& Das, 2005; Manos et al., 2007). The diversity in the board provides the necessary conduit for expanding firm operations in multiple directions (Ingley et al., 2017)5.

Specifically, when SNAs operate in an industry that is vastly dominated by a number of influential LFCs, it is strategically advantageous for them to maintain a partnering network with similar firms on its supply-chains in different sectors. Most frequently, these connections materialize through the sharing of common board directors (Bengtsson \& Kock, 1999; Elango \& Pattnaik, 2007). Over time, a mature relationship governs the current and future capital structures of firms, influencing the existing patterns of firm-interlinked investments. Afterwards, as connections consolidate and become sufficiently stable, they constitute a support system for capital structures (Booth et al., 2001; Simpson \& Gleason, 1999).

Although a number of influential LFCs 6 in India also tap opportunities for similar investments through their interlocking directorates, these are frequently limited to the firms that they currently control or those that they are in the process of acquiring in course of their business expansions. The strategic decisions are governed primarily by the influence of the family-related promoters sitting on firm boards (Khanna \& Palepu, 2000; Randolph et al., 2021; Zahra \& Pearce, 1989). Oftentimes, a onesided family diktat dominating such critical investment decisions causes a failure for the vast majority of LFC firms to attain the desired investment balance. By contrast, the balance emerges for SNAs through the strategic deployment of their interlocking ties, even when influential family connections or strong community relationships do not exist.

\section{Framework for Exploratory Analysis}

\subsection{Firm Interlock Network}

Our model is conceptualized with capital investments of firms unfolding on a network comprising $n$ firms that are connected by ties of interlocking directorate through the sharing of one or more directors on the boards 7 . A tie carries a weight proportional to the total number of shared directors on the boards. Such a network of size $n$ with $m$ ties can be characterized by an $n$-dimensional, square, symmetric weight matrix $\boldsymbol{W}: W_{i j}=W_{j i}=1,2, \ldots$, if firms $i$ and $j$ are associated by sharing a number $1,2, \ldots$ of directors; $W_{i j}=0$ otherwise. Conceptually, when two firms share many directors on their boards, their coupling strength is large compared with when they shared only a few directors. A strong sharing offers a greater opportunity for coordinated and strategic decision-making. However, a tie's directionality is irrelevant.

\subsection{Conditions for Firm Investment Behavior}

Three conditions govern firm investment behavior:

\footnotetext{
${ }^{5}$ Interlocking directorates are well-known for the management of cooperation. However, it is by no means the only possible instrument to manage cooperation and network ties for investment purposes. Nevertheless, for most firms in India, board interlocks play the most significant role in networking activities and decision-making (Bajpai, 2016).

6 Some of these firms are even members of major business groups controlled by families of industrialists or mercantile communities in the country.

7 For the present purpose, a firm and its board are largely synonymous.
} 
1. Each firm exhibits a characteristic form for the firm-specific investment.

2. Firm-specific investments are distinct from firm-interlinked investments.

3. Investment balance attains over a period when transients are smoothed out or eliminated.

Condition 1 approximates the effect that financial decisions affect each firm in a similar way in the absence of rare events, market instabilities, or turbulences. This signifies that the firm-specific investment function exhibits behavioral isomorphism. Condition 2 prohibits interactive effects to operate between the two forms of investments over the period of interest. Condition 3, which is common in most financial and macroeconomic studies, implies that the transaction-linked ties between firms take some appropriate time to consolidate, whenever they do.

\subsection{Investment Dynamics on Board Interlock Network}

The investment variable $I_{i}(t)$ represents the amount of capital expenditures made by firm $i$. A knowledge of this variable for all the firms in the network characterizes an investment state for the entire system. This quantity is shaped board interlock networks of firms, because, as already explained before, firm investment dynamics is largely dependent on-board structures. It is therefore possible to represent a specific investment configuration at time $t$ by the $n$-dimensional vector $\vec{I}(t)=$ $\left\{I_{1}(t), I_{2}(t), \ldots, I_{n}(t)\right\}$, where the index $i=1,2, \ldots, n$ runs over all firms in the network (Barrat et al., 2008; Newman, 2010).

The rate of change of $I_{i}(t)$ for firm $i$ is envisaged as a superposition of two independent investment modes: (1) firm-specific, characterized by the function $\psi_{i}\left(I_{i}\right)$ pertaining to firm $i$ 's unique, internal investment; (2) firm-interlinked, characterized by the function $\chi(\boldsymbol{W}, I)$ pertaining to firm $i$ 's investment in coordination with its supply-chain partners. The complete dynamics, then, assumes the form: $\dot{I}_{i}=$ $\psi_{i}\left(I_{i}\right)+\chi\left(W_{i j}, I_{i}\right)$, where the overdot represents time derivative. The $\chi(W, I)$ term embodies linearly additive terms in the investment: $\chi\left(W_{i j}, I_{i}\right)=\sum_{j} W_{i j} \varphi\left(I_{i}, I_{j}\right)$, where $\varphi\left(I_{i}, I_{j}\right)$ is a 2-firm, dyadic function coupling the investments of firms $i$ and $j$. To make the framework general, we take $\varphi\left(I_{i}, I_{j}\right)$ to be nonsymmetric: $\varphi\left(I_{i}, I_{j}\right) \neq \varphi\left(I_{j}, I_{i}\right)$. Additionally, by the assumption of behavioral isomorphism, we set $\psi_{i}\left(I_{i}\right)=\psi\left(I_{i}\right), \forall i=1, \ldots, n$. The complete investment dynamics now takes on a simpler appearance: $\dot{I}_{i}=\psi\left(I_{i}\right)+\sum_{j} W_{i j} \varphi\left(I_{i}, I_{j}\right)$.

\subsection{Investment Balance}

In the interfirm mode, a deficit investment amount between firms $i$ and $j$ is characterized by the 2firm function taking the form $\varphi\left(I_{i}, I_{j}\right)=\omega\left(I_{i}\right)-\omega\left(I_{j}\right)$, where $\omega(I)$ is a 1-firm function (Barrat et al., 2008; Newman, 2010). Fundamentally, it is the effect of how firm $i$ makes its investments in coordination with firm $j$. Thus, for example, as firm $j$ invests more in doing business with firm $i$, the latter, in turn, will also make proportionately large amounts of investments ${ }^{8}$.

Investment balance is characterized by a vector $\vec{\theta}=\left\{I_{i}^{*}\right\}$ for which $\dot{I}_{i}=0, \forall i=1, \ldots, n$. With differentially coupled investments, the condition $\psi\left(I_{i}^{*}\right)+\sum_{j} W_{i j} \varphi\left(I_{i}^{*}, I_{j}^{*}\right)=0$ reads: $\psi\left(I_{i}^{*}\right)+s_{i} \omega\left(I_{i}^{*}\right)-$ $\sum_{j} W_{i j} \omega\left(I_{j}^{*}\right)=0$, where $s_{i}=\sum_{k \neq i} W_{i k}$ is the strength of firm $i$ in the interlock (Barthélemy et al., 2005), and $\varsigma=\frac{1}{n} \sum_{k=1}^{n} s_{k}$ is the average strength of the complete network. Introducing a small perturbation $\vec{\eta}$

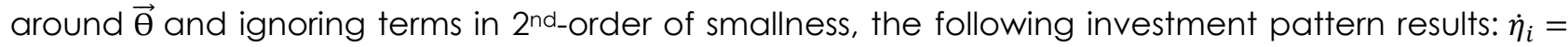
$\rho_{i} \eta_{i}+\eta_{i} \sum_{j} \sigma_{i j} W_{i j}+\sum_{j} \tau_{i j} W_{i j} \eta_{j}$. Here, $\rho_{i}=\left.\frac{d \psi\left(I_{i}\right)}{d I_{i}}\right|_{I_{i}=I_{i}^{*}}=\psi^{\prime}\left(I_{i}^{*}\right) ; \sigma_{i j}$ and $\tau_{i j}$ are derivatives of the 2-firm function with respect to its first and second arguments respectively, given by $\sigma_{i j}=\varphi_{a}\left(I_{i}^{*}, I_{j}^{*}\right)=\omega^{\prime}\left(I_{i}^{*}\right)=$

8 Firms do not make investments in this way unless they are interlocked in a governance structure in which they perform mutually advantageous business transactions in a supply-chain-linked facilitating mode. 
$U_{i}$, and $\tau_{i j}=\varphi_{b}\left(I_{i}^{*}, I_{j}^{*}\right)=-\omega^{\prime}\left(I_{j}^{*}\right)=-V_{j}$. These quantities are the model parameters, in terms of which the final equation can be expressed as $\dot{\eta}_{i}=\rho_{i} \eta_{i}+\sum_{j} \mathbb{G}_{i j} \eta_{j}$, where $\mathbb{G}_{i j}=s_{i} U_{i} \delta_{i j}-V_{j} W_{i j}$. In matrix notation, the form looks quite simple: $\dot{\vec{\eta}}=\mathbb{N} \vec{\eta}$, where $\mathbb{N}$ stands for the matrix $\rho \mathbb{I}+\mathbb{G}$.

The eigenvalues of $\mathbb{N}$ are of the form $\omega_{q}=\rho+\lambda_{q}(q=1, \ldots, r)$, where $\lambda_{q}$ is an eigenvalue of $\mathbb{G}$. In order for the balance to be stable, it is necessary that $\omega_{q}=\rho+\lambda_{q}<0$. Besides, $\lambda_{q}$ 's are known to be positive semi-definite (Olfati-Saber, 2006). This results in the condition $\rho=\psi^{\prime}\left(I^{*}\right)<0$. Importantly, the stable balance condition can be expressed fully in terms of $\lambda_{\text {lar, }}$, the leading eigenvalue of $\mathbb{G}$. Thus, the network's macrostructure is encoded in $\mathbb{G}$ through its weight matrix $\boldsymbol{W}$, which is reflected in the quantity $\lambda_{\text {lar }}$. By contrast, the network dynamics of firm-specific and the firm-interlinked investments is embedded in the two functions $\omega$ and $\psi$. Through these functions, the dynamics of the underlying network can be maintained ${ }^{9}$. Table 1 summarizes the variables and parameters used in the study.

\section{Table 1: Summary of Variables and Parameters of Firm Investments}

\begin{tabular}{cl}
\hline Symbol & Explanation \\
\hline$I_{i}$ & Investment of firm $i$ \\
$m$ & Total number of firms in interlocking directorate \\
$\boldsymbol{W}=\left\{W_{i j}\right\}$ & Total number of ties between pairs of firms in network \\
$\psi\left(I_{i}\right)$ & Firm-specific investment of firm $i$ \\
$\varphi\left(I_{i}, I_{j}\right)$ & Non-symmetric 2 -firm function coupling investments of firms $i$ and $j$ \\
$\omega\left(I_{i}\right)$ & 1-firm function for firm $i$ 's investment to coupled investments \\
$\vec{\theta}$ & Investment balance vector \\
$\rho$ & Self-induced investment pertaining to firm's investment differential \\
$\sigma, \tau$ & Firm-interlinked investment pertaining to firm's investment differential \\
$\lambda_{\text {lar }}$ & Leading eigenvalue of the graph Laplacian \\
\hline
\end{tabular}

\section{Research Setting and Data}

For this study, we used board data of publicly listed non-banking, non-finance-sector firms for the year 2014-2017 to construct the sector-specific interlock networks. This period was chosen, because it was relatively stable for the Indian economy, with practically little or no extraordinary events. Moreover, the board interlock structures of our sample of firms did not change significantly over this horizon. Board data included information about company board characteristics, the directors as well as a number of other company attributes for each company in the sample. Specific information about directors on the boards was obtained from data purchased from the Prime Database Group (http://www.primedatabase.com). For companies listed on the Bombay Stock Exchange (BSE http://www.bseindia.com) and the National Stock Exchange (NSE - http://www.nseindia.com), firmlevel data pertaining to capital investment, operational accounting, and performance were obtained from the Prowess database, which is owned, designed, and maintained by the Centre for Monitoring Indian Economy Pvt. Ltd. - (www.cmie.com). The data were subsequently cross validated against published annual financial reports of all companies included in the sample. The processed

9 This point was noted by earlier researchers in the context of general network dynamics (Barrat et al., 2008; Newman, 2010). 
data for the window 2007-2015 (inclusive) were then stored in databases constructed and designed for optimized search and retrieval.

There is sufficient early evidence that firms operating within the same industry sector exhibit similar patterns of capital structures (Bradley et al., 1984; Titman \& Wessels, 1988). For this study, we grouped our firms by major industry sectors ${ }^{10}$. For inclusive illustration and analysis in this paper, we selected the top four sectors by interlock size. These sectors are fashion (LFC = 101; SNA = 151); manufacturing (LFC = 117; SNA = 140); transport (LFC = 99; SNA = 128); and food (LFC = 93; SNA = 122), where the figures in parentheses indicate the sizes of the LFC and SNA interlock networks in the corresponding sectors (see Table 2 for details).

Historically, LFCs have played a critically important role in India's economy. Because of the country's long tradition of family- and community-controlled firms (Kumar \& Singh, 2013; Ray et al., 2018; Selarka, 2005), there is a strong connection linking these families, communities, and businesses in India (Bajpai, 2016). Nevertheless, it has sometimes been criticized that an excessive dominance exercised by these firms over the market reduces overall market efficiency and performance (Gollakota \& Gupta, 2006). On the other hand, market liberalization and constructive steps taken subsequently by market regulators such as, the Securities and Exchange Board of India or SEBI, have ameliorated the governance situation in the corporate sector. This has given rise to a significant flow of capital investments from SNAs to grow and expand in order to compete with market controlling LFCs through their board influence, range, and subsidiary deployments in the market (Bajpai, 2016).

To collect data for the sample of firms for SNA and LFC interlocks, we excluded all Indian subsidiaries of foreign multinationals as well as financial services and banking firms that adhere to different accounting standards. In conformity with the practice followed by prior researchers (Claessens \& Fan, 2002; Singla et al., 2014; Villalonga \& Amit, 2006; Ray et al., 2018), we identified a firm as LFC if the primary family has a vested stake amounting to $20 \%$ or higher in the firm, in which a member of this family sits on the firm board and/or functions as the board chair.

Our primary study variable is capital investment of firms. Following earlier convention (Ascioglu et al., 2008; Coles et al., 2006; Martin et al., 2013), we computed it as the total amount of spending on all of the following items: Land and building; plant and machinery; computers and electrical assets; transport, communication equipment, and infrastructure; furniture, social amenities, and other fixed assets $^{11}$. Finally, groups of firms were compared based on the four standard performance indicators: Return of equity (ROE); Return on assets (ROA); Tobin's Q (TQ); Price-earnings multiples (PE).

\section{Computations}

In keeping with behavioral isomorphism, we employed two separate models for the 2-firm function but keep the firm-specific investment function the same in both cases ${ }^{12}$.

\subsection{Firm-specific investments}

To find the form of the firm-specific function, we examined an empirical time series of the capital expenditures of all non-interlocked isolates in every industry sector included in the sample. In Figure

\footnotetext{
10 The sectors are listed on the National Portal of India (https://www.india.gov.in).

11 Of course, several other components may be aggregated into the total realizable capital expenditures of firms. However, for the present study, the items listed above provide an adequate approximation.

12 The bulk of the numerical work in this study was performed using routines written in the $\mathrm{C}++$ programming language and in Matlab R2013a (8.1.0.604). A few computations for the large-scale network metrics were carried out with the Pajek 4.04 (Batagelj \& Mrvar, 2015) and the Ucinet 6 (Borgatti et al., 2002) software packages.
} 
1, these plots are illustrated for two sectors: Fashion $\left(A_{2} B_{2}\right)$ and manufacturing $\left(A_{1} B_{1}\right)$. The phaseplane dynamics, exhibited in Figure 2 , is identical for both. The regions $B_{1}$ and $B_{2}$ correspond to actual time series data obtained from the manufacturing and fashion sectors respectively. The regions $A_{1}$ and $A_{2}$ correspond to unspecified initial-period investments ${ }^{13}$. For the selected firm groups in the samples, such early data were unavailable. Nevertheless, the typical early-time behavior exhibits either growth or decline in a nearly linear fashion before a saturation region is reached (Almeida \& Campello, M. 2007; Hillier \& McColgan, 2006). In time, the growth phase corresponds to incrementally rising investment amounts, and the decline phase corresponds to incrementally falling ones, assuming that investments started at some initial time $t=0$. The reason is that, the near-linear investment growth or decline persists only over a fairly short initial window, after which it begins to saturate. Following on this clue to firm's investment trends, the firm-specific function is modeled as $\psi\left(I_{i}\right)=\alpha\left(1-I_{i}\right)$, where $\alpha$ is a positive constant. In this case, the network reaches balance at $I^{*}=1^{14}$. On the interval $(0,1), \psi(I)>0$ : the flow carries the phase point to the right toward $I^{*}=1$. On $(1, \infty)$, $\psi(I)<0$ : the flow carries it to the left toward $I^{*}=1$. In either case, the phase point drifts toward $I^{*}=1$ and settles right there. The characteristic time scale of convergence is given by the quantity $\alpha^{-1}$, which characterizes the time for $I(t)$ to vary significantly around $I^{*}=1$.

\begin{tabular}{|l|l|l|}
\hline $\begin{array}{l}\text { Figure 1. Time-series of firm-specific } \\
\text { investments (unscaled) of non-interlocked } \\
\text { isolates in fashion (lower curve) and } \\
\text { manufacturing (upper curve) }\end{array}$ & $\begin{array}{l}\text { Figure 2. Phase plane diagram } \\
\text { corresponding to Figure } 1\end{array}$ \\
\hline \hline
\end{tabular}

\subsection{Firm-interlinked investments}

Early firm-interlinked investment dynamics is marked by sporadic capital expenditures during by a firm's initial negotiations and adjustments with its supply-chain partners. Since this behavior does not show isomorphism, it is not included in the study. Interest, however, focuses on the long-run balance, for which two separate models for the 2 -firm function are employed.

Model 1. By its very construction, the 2-firm function embodies a deficit: $\varphi\left(I_{i}, I_{j}\right)=\omega\left(I_{i}\right)-\omega\left(I_{j}\right)$. When the interlocked firms operate in supply-chain-linked modes, a practically reasonable 1-firm function can be represented as $\omega\left(I_{i}\right)=\beta I_{i}\left(1+I_{i}\right)^{-1}$, where $\beta$ is a positive constant. As $I \rightarrow 0$, one has $\omega \sim I$, and as $I \rightarrow \infty$, it is seen that $\omega$ approaches $\beta$ asymptotically. Since $\omega^{\prime}\left(I^{*}\right)=\beta>0$, the trivial fixed point

\footnotetext{
13 The initial periods are characteristic of the investment behavior of a firm immediately after the inception of specific projects or just after it has been listed on a stock exchange.

14 The application-specific scales used in firms' investment amounts are not of any particular significance for the present and subsequent discussions.
} 
$I^{*}=0$ is inherently unstable. Henceforth, this impractical condition will not be of any concern to this study. The actual form of the 2 -firm function is $\varphi\left(I_{i}, I_{j}\right)=\beta \frac{I_{i}-I_{j}}{\left(1+I_{i}\right)\left(1+I_{j}\right)}$. In this model, the balance emerges at $I^{*}=1$, and to reach stability, one obtains $\lambda_{\text {lar }}<\frac{4 \alpha}{\beta}$.

Model 2. In this model, the 1-firm function is taken to be $\omega\left(I_{i}\right)=I_{i}\left(\gamma+I_{j}-I_{i}\right)$, where $I_{i}, I_{j}>0$ are the investment levels of firms $i, j$ respectively, and $\gamma$ is a positive constant. Physically, this form embodies a synergistic investment relationship between firms $i$ and $j$. This signifies, for a definite level of $j$ 's investments, the corresponding investment amount of $i$ rises initially but declines subsequently. More specifically, for a given value of $I_{j}$, $i$ 's amount varies quadratically in $I_{i}$ that is zero when $I_{i}=\left\{0, \gamma+I_{j}\right\}$ and reaches a maximum of $\frac{1}{4}\left(\gamma+I_{j}\right)^{2}$ at $\tilde{I}_{i}=\frac{1}{2}\left(\gamma+I_{j}\right)$. This yields the 2 -firm function $\varphi\left(I_{i}, I_{j}\right)=\left(I_{i}-\right.$ $\left.I_{j}\right)\left(\gamma-I_{i}-I_{j}\right)$. The fixed point for the firm-specific component $\left(\vec{I}^{*}=\overrightarrow{1}\right)$ is a large-scale solution in this model. Further, $\omega^{\prime}\left(I^{*}=1\right)=\gamma-1, \psi^{\prime}\left(I^{*}=1\right)=-\alpha$, and stability is given by the condition $\lambda_{\text {lar }}<\frac{\alpha}{\gamma-1^{\prime}}$, where $\alpha, \gamma>0$. Additionally, the symmetric graph Laplacian has real, non-negative eigenvalues (Anderson \& Morley, 1985; Li \& Zhang, 1998), imposing the further restriction that $\gamma>1$, so that, ultimately, $0<\gamma<\left(\frac{1}{\lambda_{\text {lar }}}\right) \alpha$. Assuming that $\psi\left(I_{i}^{*}\right)=0$ has a solution $I_{i}^{*}=s$, one has $I_{j}^{*}=\gamma-s$. Since $I_{j}^{*} \neq$ $s$, there is a further restriction on $\gamma: \gamma \neq 2 s$.

\subsection{Numerics}

The network's structural computation rests on the graph Laplacian matrix $\mathbb{G}$. Denote the leading eigenvalue of $\mathbb{G}$ by $\lambda_{\text {lar }}^{a c t}$. The stationarity condition in model 1 is then given by $\lambda_{\text {lar }}^{a c t}<\frac{4 \alpha}{\beta}$, and the basin boundary is given parametrically by the equation $\beta=\left(\frac{4}{\lambda_{\text {lar }}}\right) \alpha$. In model 2 , the corresponding condition is $\lambda_{\text {lar }}^{a c t}<\frac{\alpha}{\gamma-1}$, and the basin boundary is given by $\gamma=\left(\frac{1}{\lambda_{\text {lar }}^{a c t}}\right) \alpha+1$. We computed the eigenvalues of $\mathbb{G}$ by tridiagonal reduction using Householder algorithm and subsequently by the diagonalization of the reduced matrix using QL algorithm (Press et al., 1992).

\subsection{Calibration}

Because their real population distributions of the model parameters were unknown, we performed Monte Carlo simulations centered on real market data, considering them as the true population (Efron \& Tibshirani, 1993; Mooney \& Duval, 1993). To do this, we selected the parameters so that the squared-errors $\left(I_{i}-I_{i}^{a c t}\right)^{2}$ were minimized over the entire sample observations. Introducing a partition of the full time window by discrete time points $\left(t_{1}, \ldots, t_{K}\right)$, we then added the errors at each time point, weighted the quantity by the measurement error $\sigma_{I_{i}}$ of each $I_{i}$, and generated an objective function of the form $\chi^{2}=\sum_{i=1}^{n} \sum_{t_{j}}\left(\frac{I_{i}\left(t_{j}\right)-I_{i}^{a c t}\left(t_{j}\right)}{I_{S_{i}}}\right)^{2}$, where $n$ is the number of variables, and $t_{j}$ is the number of sample data points. Finally, we estimated the parameters by minimizing $\chi^{2}$ by the Levenberg-Marquardt method (Press et al., 1992). The steps are as follows:

1. Using actual market data, construct the graph Laplacian $\mathbb{G}_{0}$.

2. From $\mathbb{G}_{0}$, estimate the parameters for one stable state of the dynamics. Let $\Theta_{0}$ be the parameter set $\Theta_{0}=\left(\alpha_{0}, \beta_{0}, \gamma_{0}\right\}$.

3. Resample the tie weights of the interlock network uniformly at random with replacement.

4. Choose the same number of sampled tie weights at a time and assign them to an initially unweighted configuration of the network.

5. Compute a bootstrapped $\mathbb{G}=\mathbb{G}_{1}$ for this network.

6. Use $\mathbb{G}_{1}$ as $\mathbb{G}_{0}$ 's surrogate and find the parameter set $\hat{\Theta}_{1}$ for a stable network configuration. 
7. Repeat steps $2-5$ as many times as desired to generate the parameter sampling distribution $\left\{\widehat{\Theta}_{2}, \ldots, \hat{\Theta}_{B}\right\}$.

After the successful termination of this procedure, we computed the relevant parameter confidence intervals by the percentile method (Joshi et al., 2006): If $\hat{\Theta}^{(\alpha)}$ represents the $100(1-\alpha)$ percentile, then the confidence interval is given by $\mathbb{I}=\left(\bar{\Theta}_{l}, \bar{\Theta}_{u}\right)=\left(\hat{\Theta}^{\frac{\alpha}{2}}, \widehat{\Theta}^{1-\frac{\alpha}{2}}\right)$.

\section{Results and Discussions ${ }^{15}$}

\subsection{Macro Features}

The two networks employed in this study are the board interlocks of LFCs and SNAs, restricted to separate sectors of the industry, where a sector is specified by the sector in which the primary (focal) firm operates. Table 2 displays the values of the macrostructure metrics of these networks. As already mentioned before, results from four of the largest sectors according to the sizes of their interlocks are discussed in this paper. These sectors are fashion, manufacturing, transport, and food.

Small values of the network density for both LFC and SNA interlocks, computed using the formula $\rho=$ $\frac{m}{\frac{1}{2} n(n-1)}$, indicate the sparseness of these networks (Wasserman \& Faust, 1994). The mean degrees lie in the range of $1.9-3.8$, and the mean strengths per vertex in the range $2.5-5.2$. The values for SNAs are slightly higher than those for LFCs. Overall, they signify that connection centralities of the interlocked firms are somewhat low, a result that is further corroborated by the small value of the degree centralization of the networks. The centralization measures the extent to which interlocking ties among the firms are bound to the highly connected firm boards and is computed by the formula $\sigma_{\vartheta}=\frac{\sum_{i=1}^{n}\left(k_{\max }-k_{i}\right)}{\max \left[\sum_{i=1}^{n}\left(k_{\max }-k_{i}\right)\right]}$, where $k_{\max }$ is the largest degree, $k_{i}$ is the degree of firm $i$, and max [...] gives the theoretical maximum sum of differences in the degrees in the network (Wasserman \& Faust, 1994). The low value is indicative of an interlock density that does not depend significantly on the highly connected firms. The large-scale topology of the networks shows that this characteristic is similar across LFC and SNA interlocks.

The betweenness centrality $\beta_{i}$ of firm $i$ is an indicator of the extent to which the firm lies on paths between other firms and is computed using the formula $\beta_{i}=\frac{1}{\frac{1}{2}(n-1)(n-2)} \sum_{j<k} \frac{n_{j k}^{i}}{n_{j k}}$, , where $n_{j k}^{i}$ is the number of geodesics (shortest paths) connecting firms $j$ and $k$ that pass through firm $i$, and $n_{j k}$ is the total number of geodesics between $j$ and $k$ (Wasserman \& Faust, 1994). For both LFCs and SNAs, the average betweenness scores are much higher in manufacturing, transport, and food than those in the fashion. This makes perfect sense, because the majority of the fashion firms do not span multiple other firms either within or across sectors. By contrast, the specific nature of business transactions in transport, manufacturing, and food makes most firms in these sectors overlap with multiple other firms. Moreover, in all cases, the average betweenness of LFCs is somewhat lower than that of SNAs.

Next, we measured the geodesic distance between two firms in terms of the number of interlocks between them, and on averaging over all firms, the mean distance is computed (Wasserman \& Faust, 1994). In a small-world network, this distance scales as $\ln (n)$ (Newman 2003). One may compare this with the corresponding metric of a random network consisting of $n$ firms and with a mean degree of $\vartheta$, where the distance scales as $l_{\text {rand }} \sim \frac{\ln (n)}{\ln (\vartheta)}$ (Watts \& Strogatz, 1998). A comparison

\footnotetext{
15 For considerations of space, we present complete results for the manufacturing sector only, which serves the purpose of illustration. Results for the other sectors are similar. Nevertheless, we provide aggregate results for these sectors in the appropriate places.
} 
between the mean distances of the networks under consideration and those of their random counterparts is a test for their small-worldliness (Watts, 1999; Watts \& Strogatz, 1998). Additionally, the diameters of LFCs came out to be slightly larger than those of SNAs.

Table 2: Large-scale interlock network metrics for LFC and SNA firms in four sectors: Fashion; Manufacturing; Transport; Food

\begin{tabular}{|c|c|c|c|c|c|c|c|c|c|}
\hline \multirow[t]{3}{*}{ Metric } & \multicolumn{8}{|c|}{ Sectors } & \multirow[t]{3}{*}{ Explanation } \\
\hline & \multicolumn{2}{|c|}{ Fashion } & \multicolumn{2}{|c|}{ Manufacturing } & \multicolumn{2}{|c|}{ Transport } & \multicolumn{2}{|c|}{ Food } & \\
\hline & LFC & SNA & LFC & SNA & LFC & SNA & LFC & SNA & \\
\hline$n$ & 101 & 151 & 117 & 140 & 99 & 128 & 93 & 122 & Network size (number of vertices) \\
\hline$m$ & 116 & 185 & 149 & 177 & 118 & 242 & 128 & 154 & Number of edges in network \\
\hline$\rho$ & 0.02 & 0.02 & 0.02 & 0.02 & 0.02 & 0.03 & 0.03 & 0.02 & Network density \\
\hline$\vartheta$ & 2.01 & 2.45 & 1.93 & 2.53 & 2.33 & 3.78 & 2.11 & 2.52 & Mean network degree \\
\hline$\varsigma$ & 2.91 & 3.67 & 2.71 & 3.60 & 3.06 & 5.17 & 2.46 & 3.95 & Mean network strength \\
\hline$\sigma_{\vartheta}$ & 0.02 & 0.04 & 0.05 & 0.05 & 0.03 & 0.06 & 0.03 & 0.05 & Degree centralization \\
\hline$\beta$ & 2.7 & 3.2 & 10.1 & 15.7 & 16.3 & 23.9 & 11.4 & 12.7 & Mean betweenness centrality (scaled) \\
\hline$l$ & 5.93 & 4.61 & 6.01 & 5.54 & 6.07 & 4.43 & 5.06 & 5.16 & $\begin{array}{l}\text { Mean geodesic distance (unweighted } \\
\text { network) }\end{array}$ \\
\hline$l_{\text {rand }}$ & 6.81 & 5.60 & 7.24 & 5.32 & 5.43 & 3.65 & 6.07 & 5.20 & $\begin{array}{l}\text { Mean geodesic distance (random } \\
\text { network) }\end{array}$ \\
\hline$\delta$ & 16 & 13 & 14 & 13 & 12 & 11 & 15 & 13 & Network diameter \\
\hline$C C$ & 0.53 & 0.51 & 0.39 & 0.35 & 0.38 & 0.31 & 0.50 & 0.41 & Global clustering coefficient \\
\hline$C C_{\text {rand }}$ & 0.02 & 0.02 & 0.02 & 0.02 & 0.02 & 0.03 & 0.02 & 0.02 & $\begin{array}{l}\text { Global clustering coefficient (random } \\
\text { network) }\end{array}$ \\
\hline
\end{tabular}

Finally, the fraction of transitive triads in a network is a measure of its clustering coefficient (CC). This is the probability that any two randomly selected adjacent firms of a focal firm are themselves first neighbors. We computed the CC using the Watts-Strogatz formula (Watts \& Strogatz, 1998). Again, a common comparison benchmark is the $\mathrm{CC}$ of the corresponding random network, given by the formula $C C_{\text {rand }}=\frac{\vartheta}{n}$ (Newman, 2003). As evident from Table 2, for both LFCs and SNAs, the CC's far exceed the values for their random networks. This lends additional support for the small-worldliness of both classes of networks (Watts, 1999), although the effect is slightly more prominent in SNAs.

\subsection{Investment Structures}

\subsubsection{Simulations of models 1 and 2}

As discussed earlier, the balance condition in model 1 is achieved at $I^{*}=1$ (in appropriate units). The basin boundaries separating the regions of stability and instability of the underlying dynamics represented in parameter space are displayed in Figure 3 for all interlocks. The relative significances of the parameters $\alpha$ and $\beta$ are characterized by the values of the slopes of the straight lines that demarcate the two regions, which are shown in parentheses in the legend. The entire region lying below the basin boundary is stable, and the one above it is unstable. Any point lying exactly on the line is metastable. SNA basin boundaries lie above LFC boundaries. Thus, for SNAs, more flexibility is available in the choice of the $\alpha$ 's and the $\beta$ 's. To increase visual clarity, different scales for the vertical and horizontal axes in the figure give the appearance of a much-magnified stability region. In numerical terms, the regions are actually quite small. This signifies that, small perturbations in the relative significances of $\alpha$ and $\beta$ in a stable region very close to the basin boundary might cause the 
system to slide to the unstable region. In model 2 , stability again emerges at $I^{*}=1$. The results are displayed in Figure 4 . The stability regions are comparatively smaller in this model, which renders the relative distributions of $\alpha$ and $\gamma$ even more delicate than in the previous model.

Figure 3. Basin boundaries of interlock networks in model 1

Figure 4. Basin boundaries of interlock

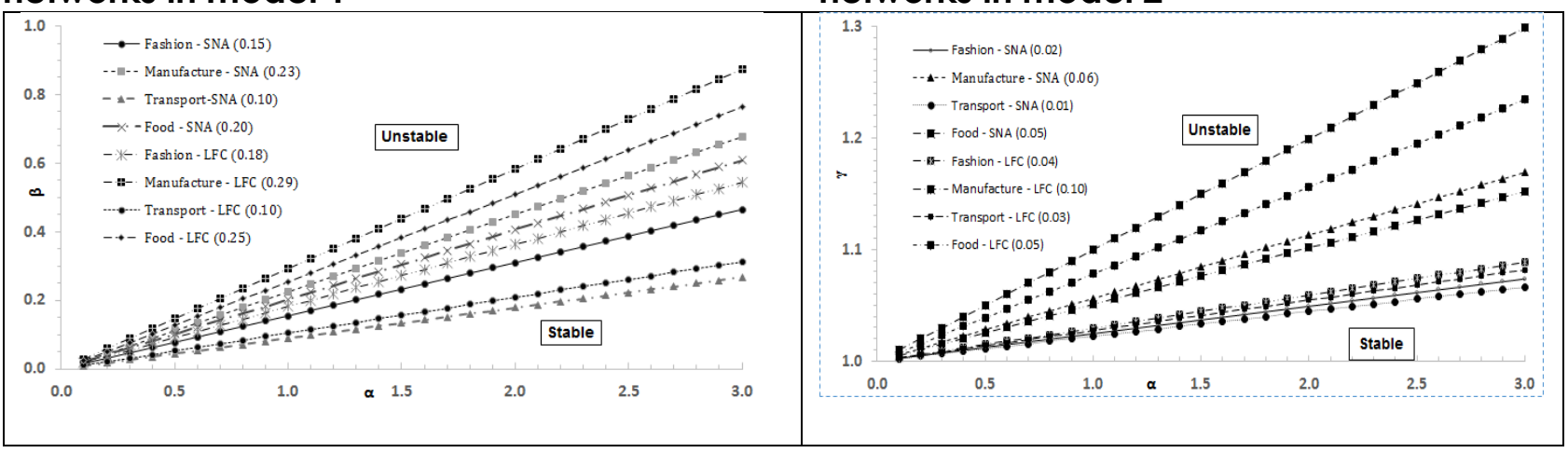

\subsubsection{Parameter significance}

It is clear from the foregoing analysis that the relative significance of the two modes of investments is limited by the size of the stability regions in parameter space. As for the first model, the investment dynamics becomes unstable when $\beta$ becomes sufficiently large to make $4\left(\frac{\alpha}{\beta}\right)$ smaller than the Laplacian's largest eigenvalue. This corresponds in practice to a situation in which interlinked investments significantly dominate firm-specific ones. It has the effect of making investments in highmean-strength, low-density networks unstable. The typical mean strength of the present networks is not overly high (Table 4). If the investment dynamics is to operate in the desired configuration, the interlinked component must be appropriately strategized. The situation is encouraging in a stablebalance configuration, because a strong, interlinked component greatly facilitates individual firms to strategize their capital expenditures quite selectively. Starting from an unbalanced configuration at some time, this has the potential to eventually raise firm-specific investments to a new level, where a stable balance obtains in the underlying investment dynamics.

\subsubsection{Monte Carlo simulations}

Figure 5. Manufacturing sector bootstraps of $\alpha$ and $\beta$ in model 1 for the SNA interlock

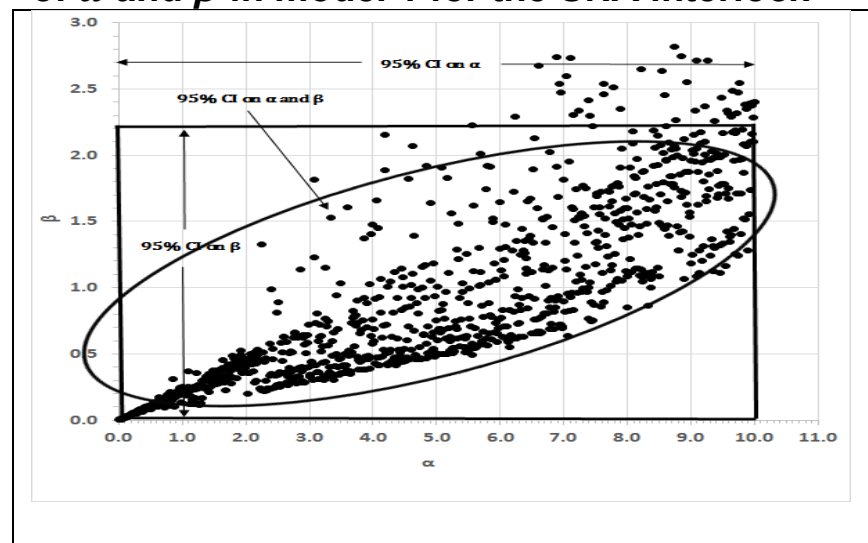

Figure 6. Manufacturing sector bootstraps of $\alpha$ and $\gamma$ in model 2 for the SNA interlock

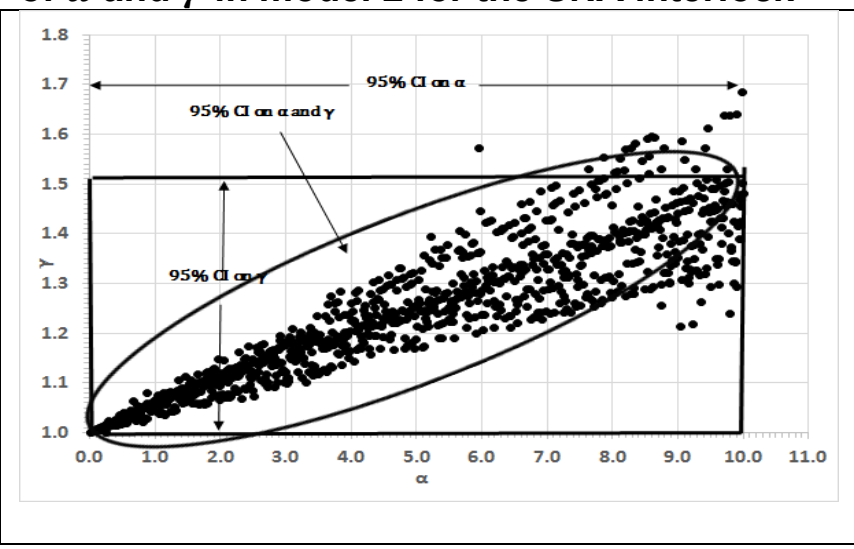


In the results of the two-parameter Monte Carlo simulations of models 1 and 2, displayed in Figures 5 and 6 for the manufacturing sector of SNA interlock, there is a clear indication of a correlation between the model parameters. For example, in Figure 5 , the $\alpha$ - $\beta$ correlation in model 1 is about 0.84 (significant at 95\%). For transport, fashion, and food, these correlations are, respectively, 0.77, 0.79 , and 0.88 , all significant at $95 \%$. Three confidence intervals (Cl) are shown in the figure, at the same level of significance. A band enclosed by two vertical lines characterize the $95 \% \mathrm{Cl}$ for $\alpha$ independent of $\beta$, and by two horizontal lines characterize a $95 \% \mathrm{Cl}$ for $\beta$ independent of $\alpha$. The joint distribution of $\alpha$ and $\beta$ is represented by an ellipse for a $95 \% \mathrm{Cl}$ (Press et al., 1992). Similar plots are shown for model 2 in Figure 6, where the $\alpha-\gamma$ correlation is close to 0.91 (significant at 95\%). Using the average value $\bar{\Theta}$ of a parameter, the range $\Lambda$ and the shape $\Gamma$ of its $\mathrm{Cl}$ can be computed by using the formulas $\Lambda=\bar{\Theta}_{u}-\bar{\Theta}_{l}$ and $\Gamma=\frac{\bar{\theta}_{u}-\bar{\theta}}{\bar{\theta}_{-}-\bar{\theta}_{l}}$ (Joshi et al., 2006). In this case, $\Gamma>1.0$ gives a shorter distance from $\bar{\Theta}$ to $\Theta_{l}$ than from $\bar{\Theta}_{u}$ to $\bar{\Theta}$. By contrast, for a normal distribution, $\Gamma=1.0$, the distribution being symmetric about $\bar{\Theta}$. In model 1 , nearly $95 \%$ of the cases had $\Gamma \approx 1.43$, and for model $2,95 \%$ of the cases had $\Gamma \approx 0.94$. Linearity is therefore ensured for manufacturing, although there is an indication of some slight deviation from linearity in model 1. For transport, fashion, and food, we obtained, respectively, $\Gamma \approx 0.92$ (model 1$), \Gamma \approx 0.94$ (model 2$) ; \Gamma \approx 1.17$ (model 1$), \Gamma \approx 0.91$ (model 2$) ; \Gamma \approx 1.28$ (model 1 ), $\Gamma \approx 1.09$ (model 2). These are, therefore, quite similar to those for manufacturing.

\subsubsection{Model Use}

With the models calibrated as described above, we next proceed to perform a comparative analysis of the market and the model behavior of aggregate investments of the firms in SNA and LFC interlocks. For considerations of space, we only consider the case of manufacturing in model 1. First, we perform a computation of the deviation amounts, in real time, of the average market values of firm investments from the stable values predicted by the models. Using the formalism described before, we perform the computations by employing the following differential equation: $\dot{\eta}_{i}=-\alpha \eta_{i}+$ $\beta \frac{\eta_{i}}{\left(1+I_{i}^{*}\right)^{2}} \sum_{k \neq i} W_{i k}-\beta \sum_{j} \frac{W_{i j} \eta_{j}}{\left(1+I_{j}^{*}\right)^{2}}$. The predicted values of the investments are then obtained from the relation $\hat{I}_{i}(t)=I_{i}^{*}+\eta_{i}(t)$, and the amount of deviation for firm $i$ is calculated as $\Delta I_{i}(t)=I_{i}^{a c t}(t)-\hat{I}_{i}(t)$, where $I_{i}^{a c t}(t)$ is the actual, market value of the investment amount of firm $i$ at period $t$. The procedure can be summarized as follows:

1. Numerically integrate the above equation over a predefined partition consisting of $n$ time points $\left(t_{1}, t_{2}, \ldots, t_{n}\right)$ to obtain the predicted values.

2. Calculate deviations by taking the difference of predicted amounts and the actual market values at the corresponding time points.

3. Select a pair of parameter values, say $\vec{\theta}_{k}=\left(\alpha_{k}, \beta_{k}\right)$, from the stable region in parameter space.

4. Using these values in the numerical integration, compute the deviation amount $\Delta I_{i}\left(t_{k}\right)=$ $I_{i}^{a c t}\left(t_{k}\right)-\hat{I}_{i}\left(t_{k}\right)$ at time $t=t_{k}$.

5. At each selected time point, compute the average deviation over a sufficiently large number, say $M$, of sample points selected uniformly at random from the stable region in parameter space, averaged over all the firms in the network, yielding the quantity: $\left\langle\Delta I\left(t_{k}\right)\right\rangle$ $=\frac{1}{M n} \sum_{s=1}^{M} \sum_{i=1}^{n} \Delta I_{i}^{\vec{\theta}_{s}}\left(t_{k}\right)$.

Figures 7 exhibits the results of these computations. The horizontal axis represents the time (in years) for the period 2007-2015. The vertical axis shows the relative absolute deviations (RAD) computed as a percent difference between the stable values predicted by the model and the median market values of investments of firms for each year. Over practically the entire window, the deviations are found to be larger for LFCs, close to $46 \%$, than for SNAs, close to $20 \%$. Deviations of approximately the same order were also found for transport, fashion, and food: Transport (LFC: $41 \%$; SNA: $21 \%$ ); Fashion (LFC: 35\%; SNA: 19\%); Food (LFC: 46\%; SNA: 24\%). 
However, it is important to remember that the stable values more accurately reflect the investment dynamics incorporated into the model unfolding on the interlocks, which is adapted to longer horizons than the present nine-year period shown here. Besides, since the market often reacts unpredictably to exogenous influences, large deviations between the actual market values and the predicted values are not entirely unexpected and do appear from time to time.

\section{Figure 7. RAD values in model 1 (manufacturing)}

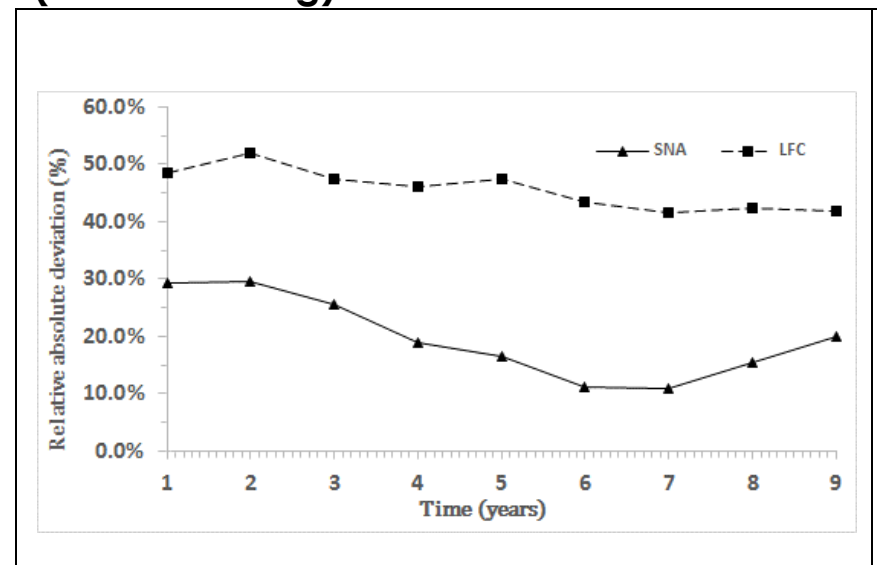

Figure 8. $\beta$-errors in model 1 (manufacturing)

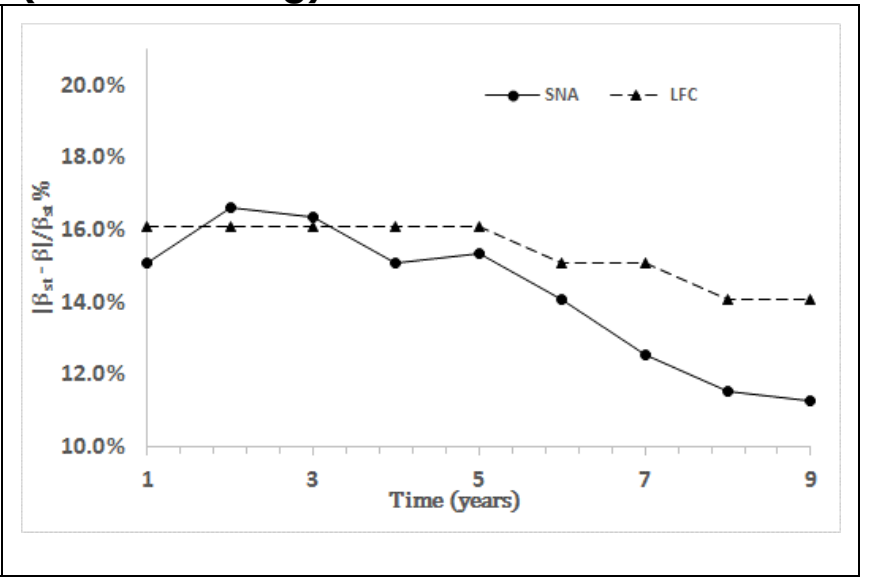

The second set of computations is based on a different approach. Here, interest focuses on the study of parameter deviations in real time from their stable values in parameter space. The procedure runs as follows:

1. For a specific choice of parameters, say $\vec{\theta}=(\alpha, \beta)$, not necessarily selected from the stable region in parameter space, compute the predicted value $\overrightarrow{I_{i}^{\theta}}\left(t_{k}\right)$ at time $t=t_{k}$ using the model.

2. Imagine that it is the actual market value at that time. In other words, for firm $i$, set $\overrightarrow{\hat{I}_{i}^{\theta}}\left(t_{k}\right)=$ $I_{i}^{*}+\eta_{i}^{\vec{\theta}}\left(t_{k}\right)=I_{i}^{\text {act }}\left(t_{k}\right)$, so that $\eta_{i}^{\vec{\theta}}\left(t_{k}\right)=I_{i}^{\text {act }}\left(t_{k}\right)-I_{i}^{*}=X_{i}$, a known quantity.

3. Taking an initial deviation, say $\eta_{i}(0)=\eta_{0}$, numerically integrate the model differential equation and obtain $\eta_{i}^{\vec{\theta}}\left(t_{k}\right)=f_{i}(\vec{\theta}, \mathrm{F})=X_{i}$, where $f_{i}(\vec{\theta}, \mathrm{F})$ is a function of the parameter vector $\vec{\theta}$ and other known quantities, represented symbolically by $\mathrm{F}$.

4. To study the behavior of only one parameter at a time, randomly select a value of $\alpha$ from the stable region in the parameter space, say $\alpha=\alpha_{s t}$, and use it in the above equation to compute the corresponding value of $\beta$.

5. Compare this $\beta$ value with the average of all permissible values of $\beta_{s t}$ corresponding to the fixed but randomly selected $\alpha_{s t}$ from the stable region in parameter space.

6. Compute the $\beta$-error as the deviation amount $\Delta \beta=\beta_{s t}-\beta$, where $\beta_{s t}=\left(\frac{2}{\lambda_{\text {lar }}}\right) \alpha_{s t}$.

7. The foregoing procedure is now executed repeatedly at each time point $t_{i}, i=1, \ldots, n$.

The results for both SNAs and LFCs are displayed in Figure 8. The $\beta$-errors lie in the range of $11-17 \%$. These are not large, signifying that there is much greater flexibility in the selection of a wide range of $\alpha_{s t}$ from $\alpha$ 's stable region in parameter space. Of course, for some periods, the $\beta$-errors may actually turn out to be large. Should this be the case, it would be necessary to turn the argument around and look for reasonably small $\alpha$-deviations by selecting appropriate $\beta_{s t}$ from $\beta$ 's stable region in parameter space. It is also evident that, overall, the $\beta$-errors for SNAs are smaller than those of LFCs. SNAs seem to have much greater flexibility in the choice of their supply-chain network of partners through the strategic appointment of independent directors on their boards. By contrast, LFCs may not always benefit from this flexibility of choice. Their boards are often overburdened by the presence 
of a large fraction of extended family members of their promoters. Some of these independent, nonexecutive directors are from firms in unrelated sectors of the market and do not have first-hand experience in the market domain in which the focal firm operates. They play only decorative roles on the board or pay lip service to the decisions taken by the promoters. This results in reduced investment efficiency and low market performance (Bajpai, 2016; Gollakota \& Gupta, 2006; Kumar \& Singh, 2013). The $\beta$-errors for transport, fashion, and food lie, respectively, in the ranges of $9-21 \%$, $13-26 \%$, and $11-23 \%$. Again, these errors are not overly large and comparable in magnitude with those for manufacturing.

\subsubsection{Firm Performance}

With the capital investment dynamics unfolding on the firm interlocks, we first computed the stable investment values of the firms according to the underlying dynamics. Next, we segregated all firms in SNA and LFC interlocks into two groups. Group $1\left(G_{1}\right)$ : Firms that attained stability according to the underlying dynamics; Group $2\left(G_{2}\right)$ : Firms that did not attain stability. We then compared the firms in these two groups on their ROE performance and computed the firm performance differential using a quantity defined as $\Delta x=\frac{x_{s t}-x_{\overline{s t}}}{x_{s t}+x_{\overline{s t}}}$, where $x_{s t}$ stands for the yearly average value of ROE for a firm that has reached stability, and $x_{\overline{s t}}$ is the value for a firm that has not reached stability.

\section{Figure 9. Performance (ROE) differentials (manufacturing)}

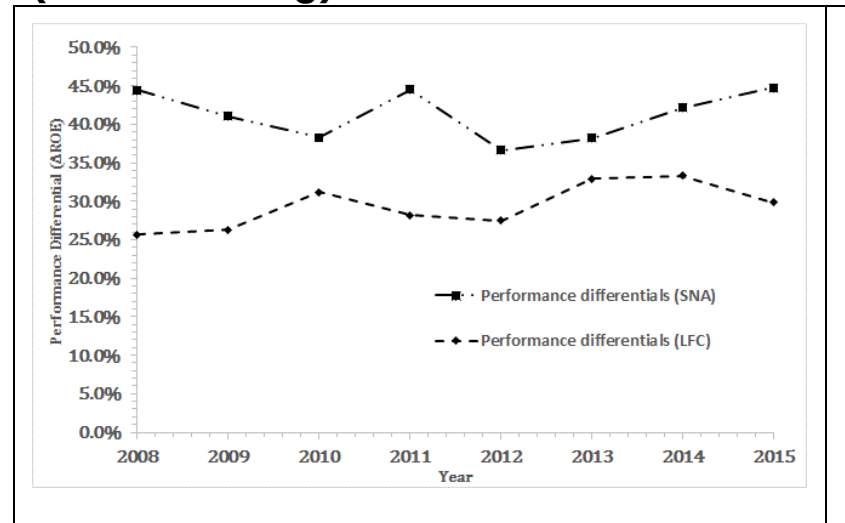

Figure 10. Performance (ROE) of firms (manufacturing)

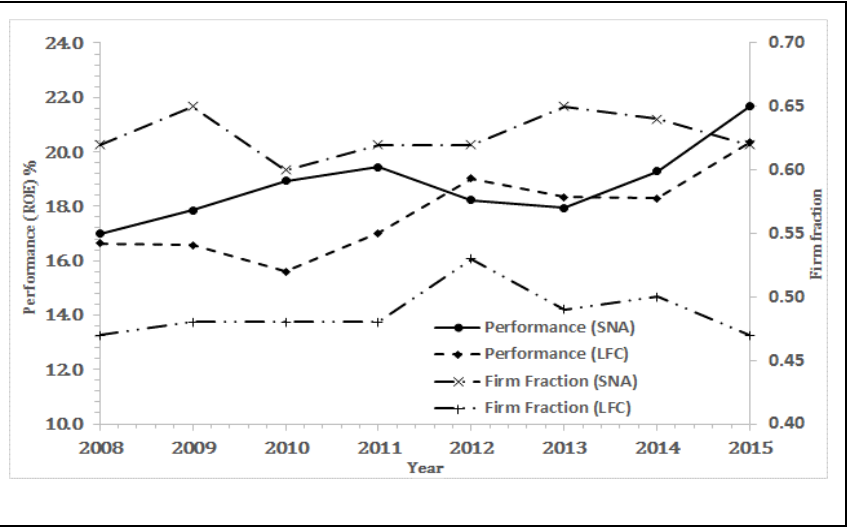

Figures 9 and 10 display the results of the performance comparison study for the manufacturing sector interlocks over a window of 2008-2015 inclusive. As Figure 9 shows, for both SNA and LFC interlocks, $G_{1}$ had consistently higher performance scores than $G_{2}$ in all the years included in the window. Besides, over the years, the performance differentials for SNAs are somewhat higher (about $12 \%$ on the average) than those for LFCs. Figure 10 displays the average ROE performance scores of the $G_{1}$ firms for both SNA and LFC interlocks. The average performance of the Gi group of firms of SNA interlock is consistently higher than that of the $G_{1}$ group of firms of LFC interlock, except in two years where LFC performance score is only $3 \%$ higher. We also obtained similar results for transport, fashion, and food. The $\mathrm{G}_{2}$ firms are not included in the performance comparison study, because their performance scores are much lower, in any case, than those of the $G_{1}$ firms for both interlocks. In Figure 10, the right-hand (secondary) vertical axis shows the fraction of firms within the group that attained stability according to the underlying investment dynamics. Fractions of SNAs are clearly much larger than fractions of LFCs in all periods. It is curious that several LFCs in the $G_{2}$ group exhibited performance closely comparable to the performance of the firms in the $G_{1}$ group. Such is not the case for SNAs. 


\subsubsection{Robustness Checks and Supplementary Analysis}

In order to gain a deeper insight into the current findings, we repeated all of the previous analyses using supplementary model 2 and additionally performed robustness checks for the results. To this end, we compared SNAs and LFCs in the two groups $G_{1}$ and $G_{2}$ on three additional measures of performance: ROA; TQ; and PE. As before, we computed, in each of the remaining three sectors (fashion, transport, and food) the firm performance differentials $\triangle x$ where $x=\{R O A, T Q, P E\}$. The results obtained from these analyses are quite similar to the above results for the ROE measure in the manufacturing sector. However, in each of the years within the selected time window, the firm fractions turned out to be somewhat large for manufacturing and fashion compared with the values obtained for transport and food. For considerations of space, these results are not included here.

\section{Limitations and Conclusion}

SNAs engaging in supply-chain networked transactions make investments in capital expenditures both individually and in cooperative association with their partner firms. Investments to meet internal demands of a firm are specific to the firm. By contrast, when functioning in interlinked modes, firms strategically align their investments in order to accommodate interfirm specificities typical in associative operations, with each firm in the interlinking chain having its portfolio of investment items.

From the current perspective, firm investments are most effective when a harmonizing balance exists between the firm-specific and the firm-interlinked forms of investment. In Indian firms, board interlocks are essential channels through which firms operate within supply-chain linkages, wherein a group of firms can adjust their investments for streamlining production or service operations as well as for minimizing fluctuations in their supply chains. Ultimately, it helps the firms to deal more effectively with uncertain demands or erratic supply problems. In some situations, financial managers are prone to plan investments under pre-set constraints. Moreover, many expenditure items are not fixed initially, and different firms tend to spend widely unequal proportions of expenditure on these items. It then becomes difficult to sustain such investments over long periods, because instabilities invariably develop in their financial systems. This is the primary justification for the use of the simulations in this study.

The present framework is predicated upon a resource-dependence view that SNAs strategically choose directors on their boards from their potential partner firms in order to have access to the critical resources of these firms. In point of fact, this is largely true for our sample of firms. Nevertheless, institution scholars have pointed out that the environments of firms are not always dependable, in that interfirm ties give rise to new dependencies and shift the balance in the firm relationship structures, such as when partner firms compete with one another for control over critical resources (Pfeffer \& Salancik, 1978; Hallen et al., 2014). If the firms in question are actually competing in some sectors, opportunistic firm behavior may result. Thus, while competing firms collaborate for shared benefits, they can simultaneously behave opportunistically to produce a power imbalance and force a partner into an unfavourable position (Agarwal et al., 2010; Gulati \& Singh, 1998) 16. This behavior can be incorporated into our study by employing a suitable economic utility function.

It is true that interlocking directorates are an effective way to strengthen strategic ties and to effectively exploit network advantages. Nevertheless, positive strategic advantages in investment decisions and increased competitiveness can also result from cooperation with strategic partners, even without shared directors on the board. Thus, in many cases, partnerships and strategic ties

\footnotetext{
16 For example, "swimming with a shark" is a situation in which a young, rising firm forges a tie with an established large firm that is potentially attractive to it and yet dangerously rivalrous (Diestre \& Rajagopalan, 2012; Hallen et al., 2014; Katila et al., 2008).
} 
signify an increase in knowledge, resources and thus also in market opportunities, even without interlocking directorates. These additional benefits can be leveraged to bolster the tie strengths used in the present formalism. On a different note, many of the adversities and challenges confronted by SNAs are the same as or are very similar to the difficulties faced by LFCs in India. These, for instance, may arise from market conditions, government decisions and policies, global economic conditions, as well as man-made or natural calamities, such as the recent Covid-19 pandemic that played havoc with the national economy. LFCs, because of their large size and financial strength, have much better advantages to deal with these issues than SNAs. Nevertheless, it may also be the case that SNAs, due to their small size and less bureaucratic structure, have advantages in some areas compared to LFCs. These issues are likely to have an influence on the performance indicators considered in the present study.

We mentioned earlier that over short initial periods, investment coordination between firms might be incomplete and somewhat unsteady. This is perfectly normal. However, because we were primarily concerned with long-run, steady-state investment behavior, our model applied best to long time frames when initial interfirm instabilities in coordinated investments have become negligible. Another issue concerns the absence of cross-level interactions between the two types of investment functions considered here. In actual practice, firm-specific investments depend somewhat on the interlinked ones. Therefore, to make the framework more general and robust, interaction effects should be included at the next higher level. This procedure, albeit computationally intensive, is conceptually clear. As far as we can see on the strength of empirical evidence at this time, we do not have a convincing causal effect of interactions between firm investments on their performance. Additional work in this direction is currently underway.

\section{References}

Almeida, H., \& Campello, M. 2007. Financial constraints, asset tangibility, and corporate investment. Review of Financial Studies, 20(5), 1429-1460.

Anderson, W. N., \& Morley, T. D. (1985). Eigenvalues of the Laplacian of a graph. Linear and Multilinear Algebra, 18(2), 141-145.

Ascioglu, A., Hegde, S. P., \& McDermott, J. B. (2008). Information asymmetry and investment-cash flow sensitivity. Journal of Banking \& Finance, 32(6), 1036-1048.

Bajpai, G.N. 2016. The Essential Book of Corporate Governance. Sage India, New Delhi.

Baiman, S., \& Rajan, M. V. 2002. Incentive issues in inter-firm relationships. Accounting, Organizations and Society, 27(3), 213-238.

Bandyopadhyay, A., \& Das, S. K. (2005). The linkage between the firm's financing decisions and real market performance: A panel study of Indian corporate sector. Journal of Economics and Business, 57(4), 288-316.

Barrat, A., Barthélemy, M., \& Vespignani, A. (2008). Dynamical Processes on Complex Networks. Cambridge University Press, Cambridge, UK.

Barthélemy, M., Barrat, A., Pastor-Satorras, R., \& Vespignani, A. (2005). Characterization and modeling of weighted networks. Physica A, 346(1-2), 34-43. 
Batagelj, V., \& A. Mrvar. 2015. Pajek-Program for Large Network Analysis. Retrieved October 2, 2015 (http://vlado.fmf.uni-lj.si/pub/networks/pajek).

Bengtsson, M., \& Kock, S. (1999). Cooperation and competition in relationships between competitors in business networks. Journal of Business \& Industrial Marketing, 14(3), 178-194.

Bidault, F., \& Salgado, M. 2001. Stability and complexity of inter-firm co-operation: The case of multipoint alliances. European Management Journal, 19(6), 619-628.

Booth, L., Aivazian, V., Demirguc-Kunt, A., \& Maksimovic, V. (2001). Capital structures in developing countries. Journal of Finance, 56(1), 87-130.

Borgatti, S. P., Everett, M. G. \& Freeman, L. C. 2002. Ucinet 6 for Windows: Software for Social Network Analysis. Harvard, MA: Analytic Technologies.

Bradley, M., Jarrell, G. A., \& Kim, E. H. (1984). On the existence of an optimal capital structure: Theory and evidence. Journal of Finance, 39(3), 857-878.

Carney, M. (2005). Corporate governance and competitive advantage in family-controlled firms. Entrepreneurship Theory and Practice, 29(3), 249-265.

Chakrabarti, R., Megginson, W. L., \& Yadav, P. K. (2008). Corporate governance in India. Journal of Applied Corporate Finance, 20(1), 59-72.

Claessens, S., \& Fan, J. P. H. (2002). Corporate governance in Asia: A survey. International Review of Finance, 3(2), 71-103.

Coles, J. L., Daniel, N. D., \& Lalitha N. (2006). Managerial incentives and risk-taking. Journal of Financial Economics, 79(2), 431-468.

Cousins, P. D., \& Menguc, B. (2006).The implications of socialization and integration in supply chain management. Journal of Operations Management, 24(5), 604-620.

Craighead, C. W., Blackhurst, J., Rungtusanatham, M. J., \& Handfield, R. B. (2007).The severity of supply chain disruptions: Design characteristics and mitigation capabilities. Decision Sciences, 38(1), 131-156.

Daily, C. M., \& Dollinger, M. J. 1992. An empirical examination of ownership structure in family and professionally managed firms. Family Business Review, 5(2), 117-136.

Efron, B., \& Tibshirani, R. J., 1993. An Introduction to the Bootstrap. Chapman and Hall, NY.

Elango, B., \& Pattnaik, C. (2007). Building capabilities for international operations through networks: a study of Indian firms. Journal of International Business Studies, 38, 541-555.

Gollakota, K., \& Gupta, V. (2006). History, ownership forms and corporate governance in India. Journal of Management History, 12(2), 185-198.

Goswami, O. (2002). Corporate governance in India. Taking action against corruption in Asia and the Pacific. In Proceedings of the $8^{\text {th }}$ European Conference on Management Leadership and Governance. Academic Publishing International Limited, Reading, UK, 85-106.

Hillier, D., \& McColgan, P. (2006). An analysis of changes in board structure during corporate governance reforms. European Financial Management, 12(4), 575-607. 
Hillman, A. J., \& Dalziel, T. 2003. Board of directors and firm performance: Integrating agency and resource dependence perspectives. Academy of Management Review, 28, 383-396.

Huggins, R. 2010. Forms of network resource: Knowledge access and the role of inter-firm networks. International Journal of Management Reviews, 12(3), 335-352.

Ingley, C., Khlif, W., \& Karoui, L. 2017. SME growth trajectories, transitions and board role portfolios: A critical review and integrative model. International Small Business Journal, 35(6): 729-750.

Jackling, B., \& Johl, S. 2009. Board structure and firm performance: Evidence from India's top companies. Corporate Governance: An International Review, 17(4), 492-509.

Joshi, M., Seidel-Morgenstern, A., \& Kremling, A. (2006). Exploiting the bootstrap method for quantifying parameter confidence intervals in dynamical systems. Metabolic Firming, 8(5), 447-455.

Kapoor, R. 2014. Collaborating with complementors: What do firms do? In R. Adner, J. E. Oxley, \& B. S. Silverman (Eds.). Collaboration and Competition in Business Ecosystems (Advances in Strategic Management, 30), 3-25. Emerald Group Publishing Limited.

Khanna, T., \& Palepu, K. 2000. Is group affiliation profitable in emerging markets? An analysis of diversified Indian business groups. Journal of Finance, 55(2), 867-891.

Khanna, T., \& Rivkin, J. W. 2001. Estimating the performance effects of business groups in emerging markets. Strategic Management Journal, 22(1), 45-74.

Klapper, L. F., \& Love, I. 2004. Corporate governance, investor protection, and performance in emerging markets. Journal of Corporate Finance, 10(5), 703-728.

Kumar, N., \& Singh, J. P. 2013. Effect of board size and promoter ownership on firm value: Some empirical findings from India. Corporate Governance: International Journal of Business in Society, 13: 88-98.

La Porta, R., Lopez-de-Silanes, F., \& Shleifer, A. (1999). Corporate ownership around the world. Journal of Finance, 54(2). 471-517.

Lee, H. L., Padmanabhan, V., \& Whang, S. (1997). Information distortion in a supply chain: The bullwhip effect. Management Science, 43(4), 546-558.

Li, J-S., \& Zhang, X-D. (1998). On the Laplacian eigenvalues of a graph. Linear Algebra and its Applications, 285(1-3), 305-307.

Manos, R., Murinde, V., \& Green, C. J. 2007. Leverage and business groups: Evidence from Indian firms. Journal of Economics and Business, 59(5), 443-465.

Martin, G. P., Gomez-Mejia, Luis R., \& Wiseman, R. M. (2013). Executive stock options as mixed gambles: Revisiting the behavioral agency model. Academy of Management Journal, 56(2), 451472.

McDonald, M. L., Westphal, J. D., \& Graebner, M. E. 2008. What do they know? The effects of outside director acquisition experience on firm acquisition performance. Strategic Management Journal, 29, 1155-1177.

Miller, D., Le Breton-Miller, I., \& Scholnick, B. (2008). Stewardship vs. stagnation: An empirical comparison of small family and non-family businesses. Journal of Management Studies, 45(1), 51-78. 
Mooney, C. Z., \& Duval, R. D., 1993. Bootstrapping: A Nonparametric Approach to Statistical Inference. Sage Publications, Newbury Park, CA.

Newman, M. E. J. (2003). The Structure and Function of Complex Networks. SIAM Review 45(2), 167256.

Newman, M. E. J. (2010). Networks: An Introduction. Oxford University Press, NY.

Nise, N. S. (2015). Control Systems Engineering. Wiley, NY.

Olfati-Saber, R. (2006). Flocking for multi-agent dynamic systems: algorithms and theory. IEEE Transactions on Automatic Control, 51 (3), 401-420.

Parmigiani, A. \& Mitchell, W. 2009. Complementarity, capabilities, and the boundaries of the firm: The impact of within-firm and interfirm expertise on concurrent sourcing of complementary components. Strategic Management Journal, 30(10), 1065-1091.

Paulraj, A., Lado, A. A., \& Chen, I. J. 2008. Inter-organizational communication as a relational competency: Antecedents and performance outcomes in collaborative buyer-supplier relationships. Journal of Operations Management, 26(1), 45-64.

Pfeffer, J., \& Salancik, G. R. 1978. The External Control of Organizations: A Resource Dependence Perspective. New York: Harper \& Row.

Press, W. H., Teukolsky, S. A., Vetterling, W. T., Flannery, B. P. 1992. Numerical Recipes in C. The Art of Scientific Computing. Cambridge University Press, NY.

Litz, R. A. 1995. The family business: Toward definitional clarity. Family Business Review, 8(2), 71-81.

Ray, S., Mondal, A., \& Ramachandran, K. 2018. How does family involvement affect a firm's internationalization? An investigation of Indian family firms. Global Strategy Journal, 8, 73-105.

Randolph, R.V., Fang, H.C., Memili, E., \& Nayir, D.Z. 2021. Family and non-family sources of knowledge diversity in family firms: The role of causation logics. International Small Business Journal, 39(1): 64-85.

Rungtusanatham, M., Salvador, F., Forza, C., \& Choi, T. Y. 2003. Supply-chain linkages and operational performance: A resource-based-view perspective. International Journal of Operations \& Production Management, 23(9), 1084-1099.

Selarka, E. 2005. Ownership concentration and firm value: A study from the Indian corporate sector. Emerging Markets Finance and Trade, 41 (6), 83-108.

Sankar, C. P., Asokan, K., \& Kumar, K. S. 2015. Exploratory social network analysis of affiliation networks of Indian listed companies. Social Networks, 43, 113-120.

Short, H. (1994). Ownership, control, financial structure and the performance of firms. Journal of Economic Surveys, 8(3), 203-249.

Simpson, W. G., \& Gleason, A. E. (1999). Board structure, ownership, and financial distress in banking firms. International Review of Economics \& Finance, 8(3), 281-292.

Singla, C., Veliyath, R., \& George, R. 2014. Family firms and internationalization-governance relationships: Evidence of secondary agency issues. Strategic Management Journal, 35(4), 606-616. 
Thomas, D. J., \& Griffin, P. M. (1996). Coordinated supply chain management. European Journal of Operational Research, 94(1), 1-15.

Titman, S., \& Wessels, R. (1988). The determinants of capital structure choice. Journal of Finance, 43(1), $1-19$.

Villalonga, B., \& Amit, R. 2006. How do family ownership, management, and control affect firm value? Journal of Financial Economics, 80, 385-417.

Wasserman, S., \& Faust, K. (1994). Social Network Analysis. Cambridge, UK: Cambridge University Press.

Watts, D. J. 1999. Networks, dynamics, and the small-world phenomenon. American Journal of Sociology, 105(2), 493-527.

Watts, D. J., \& Strogatz, S. H. (1998). Collective dynamics of "small-world" networks. Nature, 393, 440442.

Westhead, P., Cowling, M., \& Howorth, C. (2001). The development of family companies: Management and ownership imperatives. Family Business Review, 14(4), 369-385.

Young, M.N., Tsai, T., Wang, X., Liu, X., \& Ahlstrom, D. (2014). Strategy in emerging economies and the theory of the firm. Asia Pacific Journal of Management 31 (2), 331-354.

Zahra, S. A., \& Pearce, J. A. II. 1989. Boards of directors and corporate financial performance: A review and integrative model. Journal of Management, 15, 291-334. 